\title{
Editorial
}

\section{Nuevo Comité Editorial de OPA}

En este número de Óptica Pura y Aplicada inicio una nueva etapa como Editor principal de la revista y quisiera agradecer a todos los miembros de la Junta de Gobierno de SEDOPTICA y a su presidente Ignacio Moreno la confianza que han puesto en mi persona. En esta nueva etapa me acompaña como secretario Josep Ferre-Borrull, compañero de Departamento y grupo de investigación de la Universitat Rovira i Virgili de Tarragona a quien debo agradecerle que haya aceptado acompañarme en estas labores. Iniciamos este viaje con gran ilusión y responsabilidad, esperando poder contribuir e incrementar el impacto y prestigio de la revista.

No estamos solos en el comité editorial, que se completa con Juan Ignacio Albert como secretario de producción, 18 Editores Asociados pertenecientes a diversas secciones temáticas, 10 miembros del comité asesor científico y 9 asesores internacionales. No podemos olvidarnos de los revisores que contribuyen a la mejora de los trabajos publicados. A todos ellos les agradezco su participación y ayuda en hacer avanzar y mejorar la revista OPA.

David Mas Candela ha sido un excelente Editor y gran parte del éxito de OPA es suyo. Quisiera agradecerle toda la buena disposición y ayuda que me ha prestado durante esta transición de varios meses. Probablemente continuaré necesitando de sus buenos consejos y experiencia en un futuro. Quisiera destacar que durante su larga etapa en OPA, la revista ha evolucionado en todos los sentidos y se ha consolidado como una revista científica de calidad que aparece referenciada en bases de datos internacionales como Scopus, SJR o Emerging Sources Citation Index. La página web de OPA es un gran avance de gestión, pero también para visibilizar y difundir los trabajos y actividades de SEDOPTICA. Todos los artículos pueden consultarse online y tienen su referencia DOI que permite ser identificado y referenciado de manera única.

Finalmente, aprovecho la ocasión para animaros a enviar artículos de investigación o revisión, reseñas históricas, informes sobre políticas científica o resúmenes de Tesis Doctorales, todo ello relacionado con la óptica.

Tarragona, Junio 2019

Lluís F. Marsal

Editor de Óptica Pura y Aplicada

DOI: 10.7149/OPA.52.2.i 